\title{
SELAGINELLA RZEDOWSKII, UNA NUEVA ESPECIE DE SELAGINELA HETEROFILA DEL ESTADO DE GUERRERO, MEXICO.*
}

\author{
FRANCISCO G. LOREA-HERNANDEZ**
}

\section{RESUMEN}

Una nueva especie de Selaginella (S. rzedowskii) se describe del estado de Guerrero, México. Con esta especie, el número de selaginelas heterófilas con rizóforos dorsales del estado, se ha incrementado a cuatro.

S. rzedowskii difiere de las especies relacionadas por su afinidad a clima cálido y seco, y por poseer hojas medias no auriculadas ni peltadas, hojas laterales imbricadas sobre el tallo y estróbilos con la mitad basal ocupada por megasporangios.

\section{ABSTRACT}

A new species of Selaginella (S. rzedowskii) is described from the state of Guerrero, Mexico. Taking into account this species, the number of heterophyllous selaginellae with dorsal rhizophores of the state has been increased to four.

S. rzedowskii differs from the allied species by his affinity to warm and dry climate and by possesing median leaves neither auriculate nor peltate, lateral leaves imbricate on the stem and strobili with the basal half occupated by megasporangia.

La cuenca del río Zopilote (entre Chilpancingo y Mezcala), en el estado de Guerrero, es conocida desde hace mucho tiempo por la gran diversidad de comunidades vegetales que se estıblecen a lo largo de sus gradientes altitudinal y climático, que van de los 550 a los $2700 \mathrm{msnm}$, y del tipo BS al C(w), respectivamente.

Entre los 550 y los $1560 \mathrm{msnm}$, donde predomina el clima tipo $\mathrm{BS}_{1}(\mathrm{~h}) \mathrm{w}$ "(w) ig (Garcia, 1973), prospera el bosque tropical caducifolio (sensu Rzedowski, 1978.), con especies como: Baubinia andrieuxi, Bursera aptera, B. bolivari, B. fagaroides, B.

* Trabajo aceptado para su publicación en abril de 1983.

** Herbario de la Facultad de Ciencias (FCME), UNAM. A. P. 70-399 04510 México, D. F. 
lancifolia, B. longipes, B. morelensis, B. xocbipalensis, Ceiba parvifolia, Comocladia mollisima, Cordia aelaegnoides, Cyrtocarpa procera, Karwinskia mollis, Neobuxbaumia mezcalaensis, Plumeria rubra y Pseudosmodingium perniciosum, entre otras.

Los suelos en que se presenta el tipo de vegetación referido derivan, sobre todo, de rocas sedimentarias (lutitas y calizas principalmente), y son en general someros y pedregosos.

Bajo estas condiciones ecológicas, y por lo común, en sitios donde la roca caliza por ciertos mecanismos de intemperismo ha dado lugar a la formación de "caliche", se ha encontrado una nueva selaginela heterófila para México, la cual se dedica al Dr. Jerzy Rzedowski por su inapreciable labor desarrollada para el mejor conocimiento de la vegetación y flora del país.

Selaginella rzedowskii Lorea, sp. nov.

Herba reptans, ad solum adpressa, rhizophoris dorsalibus; folia dimorpha; folia media lanceolata, leviter acuminata, falciformia, margine supero interno serrulata, externo integra vel serrulata, dimidio infero ciliata, non auriculata, ca. $0.79 \mathrm{~mm}$ lata, $1.87 \mathrm{~mm}$ longa; folia lateralia ovata, apice rotundata vel aliquot acuta, basi inaequalia, marginis dimidio supero serrulata, dimidio basali ciliata, super caulem imbricata, ca. $1.1 \mathrm{~mm}$ lata, $2.3 \mathrm{~mm}$ longa; folia axillaria lateralium similia sed paulo minora; strobili ca. 1.6 $\mathrm{mm}$ lati, $12 \mathrm{~mm}$ longi, megasporangiis plerumque strobili dimidium inferum occupantis; sporophylla late ovata, acuminata, basi sagittata, peltata, marginis dimidio supero serrulata, dimidio basali ciliata, ca. $1.6 \mathrm{~mm}$ lata, $2.6 \mathrm{~mm}$ longa.

Hierba rastrera, adpresa al suelo, con un sistema de tallos principales que llevan ramitas que se dividen dicotómicamente, aparentemente no articulados; rizóforos dordos medias (dorsales) y dos laterales (ventrales); hojas medias lanceoladas, levedicotomías sucesivas en que se presentan; hojas dimórficas, dispuestas en cuatro hileras, sales, saliendo hacia atrás y hacia abajo y alternándose a izquierda y derecha en las mente acuminadas, ascendentes, falciformes, el margen superior interno serrulado, el externo entero a serrulado, margen de la mitad inferior corto a largamente ciliado, ciliadas en la base, no auriculadas, de (0.6)-0.79-(0.84) mm de ancho por (1.6)-1.87(2.1) $\mathrm{mm}$ de largo; hojas laterales ovadas, redondeadas a levemente agudas en el ápice, desiguales en la base, lado superior de la base más amplio, dispuestas en un ángulo menor de $45^{\circ}$ con respecto al tallo, margen de la mitad superior poco a notoriamente serrulado, margen de la mitad basal ciliado, imbricadas sobre el tallo, de (0.82)-1.1-(1.26) $\mathrm{mm}$ de ancho por (1.88)-2.3-(2.66) $\mathrm{mm}$ de largo; hojas axilares similares a las laterales, de (0.76)-0.98-(1.14) $\mathrm{mm}$ de ancho por (1.72)-2.1-(2.66) $\mathrm{mm}$ de largo; estróbilos angostamente oblongos a lineares, de (1.5)-1.6-(1.8) mm de ancho por (8.3)-12-(16.5) mm de largo, por lo común los megasporangios ocupan su mitad inferior, aunque a veces se presentan 1 a 4 microsporangios basales o excepcionalmente se disponen en dos hileras de megasporangios y dos de microsporangios opuestas; esporófilas isomórficas, ampliamente ovadas, acuminadas, sagitadas en la base, peltadas, margen de la mitad superior serrulado, ciliado en la mitad basal, de (1.4)-1.6-(1.8) $\mathrm{mm}$ de ancho por (2.36)-2.6-(2.72) $\mathrm{mm}$ de largo; megasporangios tetraédricos, de (0.84)-0.96-(1.06) mm por lado, siempre con cuatro megasporas; microsporangios reniformes, de $0.84 \mathrm{~mm}$ de ancho por $0.46 \mathrm{~mm}$ de alto; megasporas estriadas a ruguladas, de $0.42 \mathrm{~mm}$ de diámetro en vista polar, de color amarillo pálido 

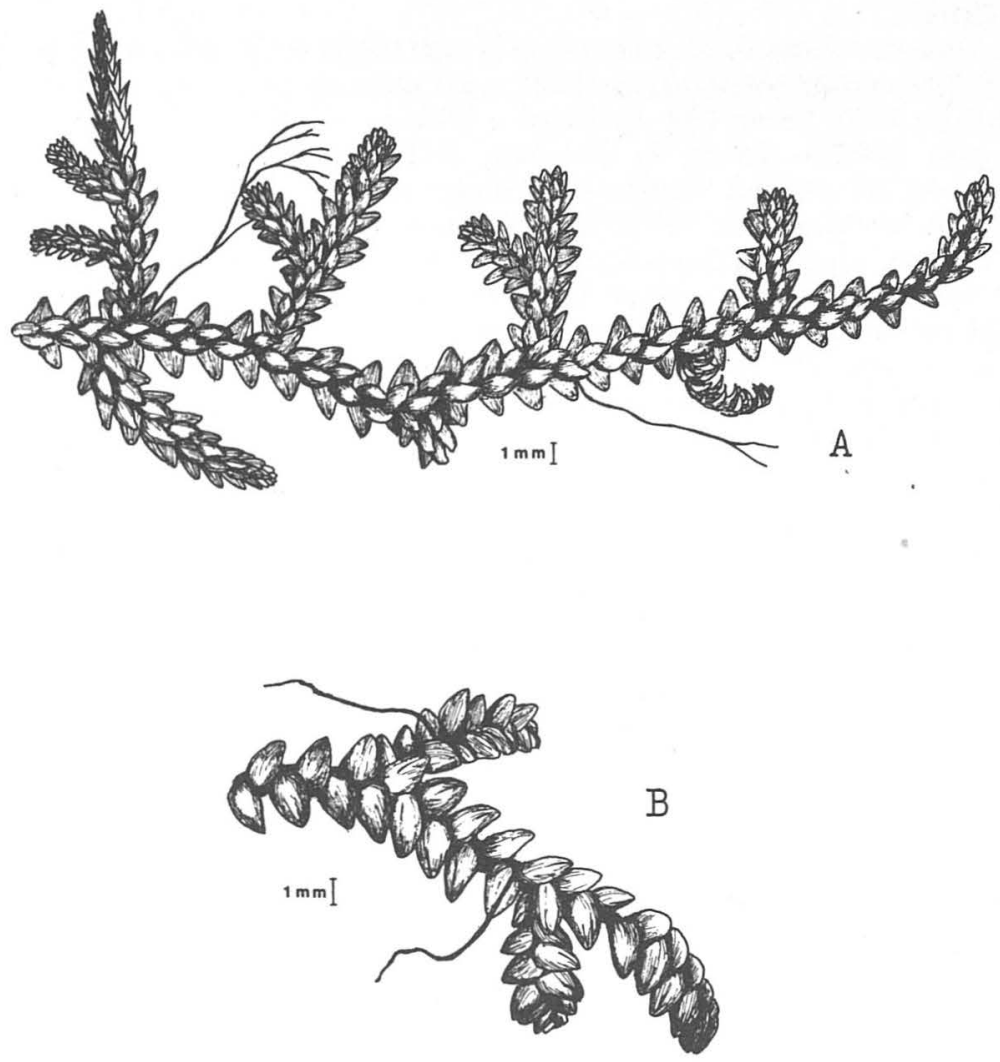

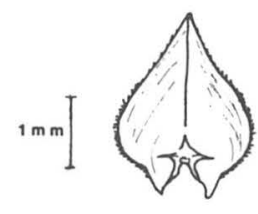

C

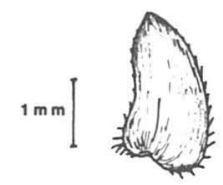

D

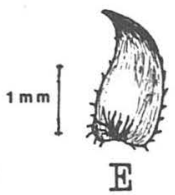

$\mathrm{E}$

Selaginella rzedowskii. A. Aspecto general de la planta. B. Vista ventral. C. Vista abaxial de una esporófila. D. Vista adaxial de una hoja ventral. E. Vista adaxial de una hoja media. 
a claro; microsporas ruguladas, agrupadas en tétradas de $0.05 \mathrm{~mm}$ por lado, de color naranja claro.

Tipo: México: Estado de Guerrero: $2 \mathrm{Km}$ al ENE de Xochipala, Mpo. de Zumpango del Río, bosque tropical caducifolio, suelo derivado de calizas, $1090 \mathrm{msnm}$. 7 de Septiembre de 1980. Lorea 834 (holotipo e isotipos: FCME).

Paratipos: México: Estado de Guerrero: $200 \mathrm{~m}$ al E de Venta Vieja, Mpo. de Zumpango del Río, bosque tropical caducifolio, suelo derivado de calizas, $700 \mathrm{msnm}$ aprox. 12 de Septiembre de 1980. J. L. Contreras 609 (FCME); $4 \mathrm{Km}$ al SE de Valerio Trujano, Mpo. de Zumpango del Río, bosque tropical caducifolio, suelo derivado de lutitas?, $450 \mathrm{msnm}$ ? 30 de Junio de 1980. J. L. Contreras 338 (FCME); $5.5 \mathrm{Km}$ al NE de Xochipala, Mpo. de Zumpango del Río, bosque tripical caducifolio. 2 de Julio de 1980. D. Sánchez y J. Saldívar 21 (FCME).

Hasta ahora se conocían tres especies heterófilas con rizóforos dorsales en Guerrero (Alston, 1955; Gregory y Riba, 1979; Smith, 1981) Selaginella galeottii, S. marginata y $S$. sertata.

La especie aquí descrita difiere por la presencia de hojas medias no auriculadas ni peltadas, hojas laterales imbricadas sobre el tallo y estróbilos con la mitad inferior ocupada por megasporangios generalmente, en oposición a las otras especies mencionadas, que poseen hojas medias auriculadas o peltadas, hojas laterales no imbricadas sobre el tallo y estnóbilos con un solo megasporangio basal.

Se distingue también por su afinidad a clima cálido seco, en tanto que las otras especies prosperan más bien en clima cálido y húmedo.

Para separar Selaginella rzedowskii de las especies relacionadas se propone la siguiente clave.

Hojas medias peltadas o auriculadas; hojas laterales no imbricadas sobre el tallo.

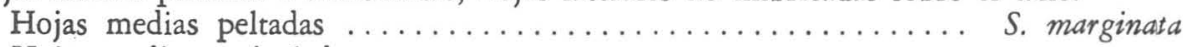

Hojas medias auriculadas.

Tallos principales flageliformes en el ápice; hojas medias con una sola auricula

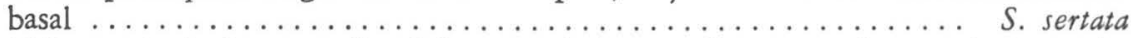
Tallos principales no flageliformes; hojas medias con dos auriculas sub-

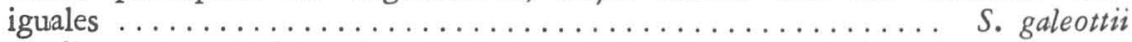
Hojas medias no peltadas ni auriculadas; hojas laterales imbricadas sobre el tallo

S. rzedowskii

\section{AGRADECIMIENTOS}

Al Dr. J. Rzedowski y al Dr. R. Riba por la revisión que hicieron del texto y por sus valiosas sugerencias.

A Marcela Villalobos por las ilustraciones.

\section{BIBLIOGRAFIA}

ALSTON, A.H.G. 1955. The Heterophyllous Selaginellae of Continental North America. Bull. British Museum (Nat. Hist.) 1(8): 221-274.

GARCIA, E. 1973. Modificaciones al Sistema de Clasificación Climática de Koppen. Instituto de Geografía. UNAM. México. 
GREGORY, D. \& R. RIBA. 1979. Selaginellaceae in Flora de Veracruz 6. INIREB Xalapa, Veracruz.

RZEDOWSKI, J. 1978. Vegetación de Mexico. Limusa. México.

SMITH, A. R. 1981. Flora of Chiapas, part. 2: Pteridophytes. Calif. Acad. Sciences. 